\title{
A New Era and Advances in Renal Cell Carcinoma
}

\author{
Y Ahmed ${ }^{1 *}$, N Osman ${ }^{2}$, R Sheikh ${ }^{1}$ and Hawa Ebrahem ${ }^{3}$ \\ ${ }^{1}$ Department of Medical Oncology, Sligo University Hospital, Europe \\ ${ }^{2}$ Department of Medical Oncology, University Hospital Limerick, Europe \\ ${ }^{3}$ Our Lady's Hospice, Harold Cross, Dublin 6, Ireland
}

Submission: August 06, 2017; Published: August 17, 2017

"Correspondence Address: Yasar Ahmed, Department of Medical Oncology, Sligo University Hospital, Sligo, Ireland, Europe, Tel: +353871022059; Email: drhammor@gmail.com

\begin{abstract}
Renal cell carcinoma is one of the most diverse cancers in terms of its natural biology and a leading cause of cancer-related death. All experts agree that a clinical trial, if available, should be considered as a first option for any patient with advanced renal cell carcinoma. Managing advanced renal cell carcinoma has become far more complex. With the availability of multiple new agents and additional targeted therapies on the horizon, selecting the optimal treatment and optimal sequence of treatments, for individual patients with metastatic renal cell carcinoma has become more challenging for clinicians. This article explores the patient- and disease-related factors that should be considered when planning mRCC treatment and discusses the latest clinical evidence for available therapeutic options.
\end{abstract}

Abbreviations: mRCC: metastatic renal cell carcinoma; IFN: Interferon; TKIs: Tyrosine kinase Inhibitors; VEGF: Vascular Endothelial Growth Factor; VEGF: Vascular Endothelial Growth Factor; PD-1: Programmed Death-1; ccRCC: Clear-Cell Histology; MSKCC: Memorial Sloan Kettering Cancer Center; OS: overall survival; IMDC: International Metastatic Renal Cell Carcinoma Database Consortium; NCCN: National Comprehensive Cancer Network ; HRQOL: Health-Related Quality-of Life

\section{Introduction}

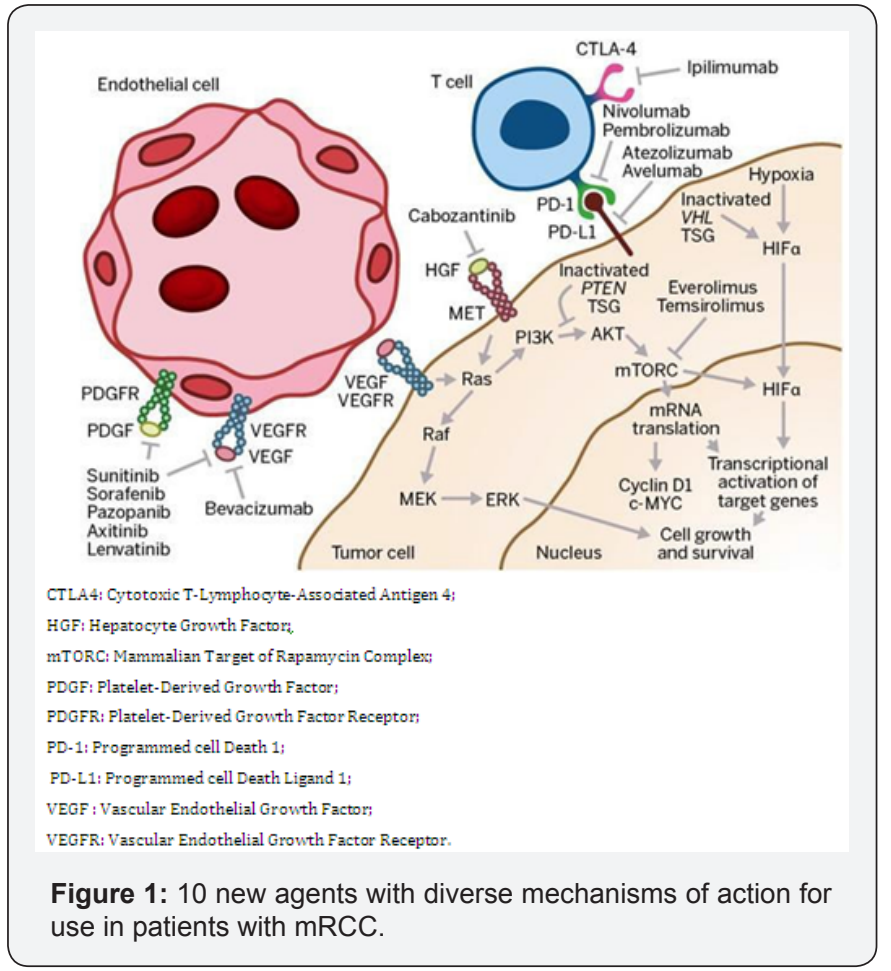

Prior to the development of targeted agents for metastatic renal cell carcinoma(mRCC), nonspecific immuno therapy with cytokines such as interferon (IFN) and interleukin-2(IL-2) was the standard of care for patients with this condition, and these therapies continue to play a role in mRCC treatment $[1,2]$. Since late 2005, however, the United States (US) Food and Drug Administration (FDA) has approved 10 new agents with diverse mechanisms of action for use in patients with mRCC (Figure 1), $[1,3,4]$. Agents directed against the vascular endothelial growth factor (VEGF) signaling pathway include the small-molecule VEGF receptor (VEGFR) tyrosine kinase inhibitors (TKIs) axitinib, cabozantinib, lenvatinib (approved in combination with everolimus), pazopanib, sorafenib, and sunitinib, and the antiVEGF antibody bevacizumab (approved in combination with IFN) [4-6]. Additionally, agents that target the mammalian target of rapamycin (mTOR) signaling pathway include temsirolimus and everolimus. 4 Finally, nivolumab is the first agent in the new class of programmed death-1 (PD-1)-targeted immune check point inhibitors to be approved for use in mRCC [4,7]. Several additional immune checkpoint inhibitors are under investigation in mRCC [8].

\section{Discussion}

\section{Selecting First-Line Therapy}

Histology: Histologic subtype is an important consideration form RCC treatment [9]. Approximately $75 \%$ to $80 \%$ of patients with RCC have clear-cell 
histology (ccRCC) [2]. For patients with non-ccRCC histology, however, the prognosis is poor, and evidence from phase 3 trials to guide optimal treatment selection is limited. The exception is emsirolimus, which is recommended as a Category 1 option for both patients with ccRCC or non-ccRCC and poor prognostic features [1]. Other patients with non-ccRCC should be considered for enrolment in a clinical trial [2,9]. If no trials are available or trial enrolment is not feasible, patients with non-ccRCC histology can be treated according to guidelines for patients with ccRCC.

\section{Prognostic Factors}

Upfront treatment plans form RCC are determined after patients are categorized according to prognostic risk, and recommendations differ for patients with favorable/ intermediate risk versus those with poor risk $[1,2,9]$. Current prognostic models incorporate multiple patient and disease characteristics to provide a reference for overall risk and expected survival.

Additional characteristics such as tumor burden and rate of progression may influence treatment selection [10]. Patient preferences and attitudes toward risk should also be considered to optimize the selection of individualized treatment from multiple evidence-based options [2]. The most widely used prognostic model in current practice was developed at the Memorial Sloan Kettering Cancer Center (MSKCC) in 1999 and revised in 2002 [1,11,12]. The MSKCC model incorporates 5 risk factors for worse survival in patients with mRCC. Based on the number of risk factors present, mRCC can be categorized into: Favorable: 0 risk factors; Intermediate: 1-2 risk factors; Poor: 3-5 risk factors.

Table 1: Prognostic Models in mRCC.

\begin{tabular}{|c|c|}
\hline $\begin{array}{c}\text { 5 Risk Factors for Worse } \\
\text { Survival }\end{array}$ & $\begin{array}{c}\text { 6 Risk Factors for Worse } \\
\text { Survival }\end{array}$ \\
\hline $\begin{array}{c}\text { Short time from diagnosis to } \\
\text { start of treatment }(<1 \text { year })\end{array}$ & $\begin{array}{c}* \text { Short time from diagnosis to } \\
\text { start of treatment }(<1 \text { year })\end{array}$ \\
\hline Low KPS $(<80 \%)$ & $*$ Low KPS $(<80 \%)$ \\
\hline *Anemia & $*$ Anemia \\
\hline *Hypercalcemia & *Hypercalcemia \\
\hline Favourable (0 risk factors), & Favourable: 0 risk factors, \\
\hline intermediate (1-2risk factors), & Intermediate: 1 -2 risk Poor: $3-6$ \\
\hline poor(3-5 risk factors) & risk factors \\
\hline
\end{tabular}

KPS: Karnofsky Performance Status; LDH: Lactate Dehydrogenase; LLN: Lower Limit of Normal; ULN: Upper Limit of Normal

External validation and comparison with other models of the International Metastatic Renal-Cell Carcinoma Database Consortium prognostic model: a population-based study. National Comprehensive Cancer Network (NCCN) Clinical Practice Guidelines in Oncology for Kidney Cancer, v2. 2017.

The MSKCC criteria were validated in the era of cytokine treatment (IL-2 and IFN), when the median overall survival (OS) for patients with favorable, intermediate, and poor risk was 30 months, 14 months, and 5 months, respectively [12]. The International Metastatic Renal Cell Carcinoma Database Consortium(IMDC), another prognostic model, was developed in 2009 and revised in 2013 to reflect clinically relevant prognostic factors in the era of VEGFRTKI therapy (Table 1) [13,14]. The IMDC model includes 6 risk factors, with risk groups defined as: Favorable: 0 risk factors; Intermediate: 1-2 risk factors; Poor: 3-6 risk factors.

The median OS for these groups is 43.2 months, 22.5 months, and 7.8 months, respectively [14]. Although the IMDC model was developed to guide first-line targeted therapy form RCC, the prognostic value of the model has also been validated in candidates for second-and third-line targeted therapy $[15,16]$ (Table 1).

Most patients with previously untreated mRCC are classified as having favorable or intermediate risk and have arrange of options for first-line treatment [2]. The National Comprehensive Cancer Network (NCCN) recommend stem sirolimus as first-line therapy for patients with poor prognosis based on clinical trial data that showed significant improvement in O Sin poor-risk patients. Subgroup analyses of poor-risk patients from pazopani band sunitinib trials also show improvement in OS, and these drugs can be substituted for temsirolimus in these patients $[9,17,18]$.

\section{Recommendations for First-Line Treatment}

The strength of clinical evidence supporting specific treatment choices should be considered. In the NCCN clinical practice guidelines, Category 1 recommendations are based on high-level evidence with uniform expert consensus regarding the appropriateness of therapy 1 . Category 2 recommendations are based on lower-level evidence, resulting in uniform (2A) or non uniform (2B) consensus regarding treatment appropriateness. At present, the NCCN recommends the preferred use of pazopanib or sunitnib as first-line treatment for Metastatic ccRCC (mccRCC) (Table 2) [1].

Table 2: Recommendations for First-Line Treatment in mRCC.

\begin{tabular}{|c|c|c|}
\hline Agent & Class & Category/preference \\
\hline Pazopanib & VEGFRTKI & Category 1 , preferred \\
\hline Sunitinib & VEGFRTKI & Category 1 , preferred \\
\hline $\begin{array}{l}\text { Bevacizumab/ } \\
\text { IFN }\end{array}$ & $\begin{array}{l}\text { Anti-VEGF } \\
\text { antibody/ } \\
\text { immunotherapy }\end{array}$ & Category 1 \\
\hline Temsirolimus & mTOR inhibitor & $\begin{array}{l}\text { Category } 1 \text { for poor-prognosis } \\
\text { patients Category } 2 \mathrm{~B} \text { for select } \\
\text { patients in other risk groups }\end{array}$ \\
\hline Axitinib & VEGFRTKI & Category 2A \\
\hline High-doseIL-2 & Immunotherapy & $\begin{array}{c}\text { Category } 2 \mathrm{~A} \text { for highly select } \\
\text { patients }\end{array}$ \\
\hline Sorafenib & VEGFRTKI & Category $2 \mathrm{~A}$ for select patients \\
\hline
\end{tabular}




\section{Cancer Therapy \& Oncology International Journal}

Patients with relapsed or medically unrespectable stage IV disease with predominant clear-cell histology.IFN=interferon; IL-2=interleukin2; mTOR=mammalian target of rapamycin; TKI=tyrosine kinase inhibitor; VEGF=vascular endothelial growth factor; VEGFR=vascular endothelial growth factor receptor. Derived from National Comprehensive Cancer Network (NCCN) Clinical Practice Guidelines in Oncology for Kidney Cancer, v2. 2017.

\section{Sunitinib}

Sunitinib is a novel VEGFRTKI approved or the first-line treatment of mRCC1. In a multinational phase 3 trials, 750 patients with previously untreated mcc RCC were randomly assigned $1: 1$ to sunitinib or IFN- $\alpha 19$. Most patients (93\%) had favorable or intermediate MSKCC risk features. Sunitinib significantly lengthened the median progression free survival (PFS) by 6 months compared with IFN $\alpha$ (11monthsvs5months; HR, 0.42; 95\% CI, 0.32-0.54; $\mathrm{P}<.001$ ). The most common grade 3-4 AEs occurring with greater frequency in the sunitinib arm were neutropenia (12\%), thrombocytopenia (8\%), hypertension (8\%), hyper amylasemia (5\%), diarrhea (5\%), and hand-foot syndrome (5\%). Grade3-4 fatigue was more common with IFN- $\alpha$ than with sunitinib (12\% vs $7 \%$ ) [19]. In an updated analysis, sunitinib showed a strong but statistically non significant trend toward improved OS [20]. The median OS was 26.4 months in the sunitinib arm and 21.8 months in the IFN- $\alpha$ arm (HR, 0.82; 95\% CI, 0.67-1.00; $\mathrm{P}=.051$ ). Of note, among patients initially randomized to IFN- $\alpha, 33 \%$ crossed over to sunitinib, and $32 \%$ received another VEGF-targeted therapy during follow-up, potentially confounding the survival analysis.

An international expanded-access trial evaluated sunitinib in 4,543 patients who were ineligible for the sunitinib registration trials, including patient saged 65 years or older (33\%) and those with poor performance status (14\%), non-ccRCC histology (12\%), and brain metastases (7\%) [18]. Overall, $26 \%$ of patients were classified as having poor prognosis according to MSKCC criteria. The majority of patients received prior systemic therapy, including cytokine therapy (68\%) and antiangiogenic therapy (10\%). The median PFS was 9.4 months, and the median OS was 18.7 months. The most common grade 3-4 AEs in this higher risk cohort were thrombocytopenia $(10 \%)$, fatigue $(9 \%)$, asthenia (7\%), neutropenia (7\%), and hand-foot syndrome (7\%) .

\section{Pazopanib}

Pazopanib is an oral angiogenesis inhibitor that targets c-KIT, PDGFR- $\alpha$ and $-\beta$, and VEGFR-1,-2, and-31. Pazopanib was approved for the treatment of patients with advanced RCC based on findings from an international, multicenter, phase 3 study of 435 patients with advanced RCC [21,22]. Patients had no prior systemic therapy, with the exception of 1 prior cytokine-based treatment, and were randomly assigned 2:1 to pazopanib or placebo [21]. Pazopanib significantly prolonged PFS compared with placebo in the entire study cohort (9.2 months vs. 4.2 months). In the subgroup of treatment-naïve patients $(\mathrm{n}=233)$, the PFS was 11.1 months with pazopanib and 2.8 months with placebo (HR, 0.40; 95\% CI, 0.27-0.60; $\mathrm{P}<.0001)$. In the pazopanib group, the most common grade3-4AEs were diarrhea and hypertension ( $4 \%$ for each). In addition, $53 \%$ of pazopanibtreated patients had increased alanine transaminase (ALT) and as partate transaminase (AST) levels of any grade, underscoring the importance of liver function monitoring during treatment [22].

Pazopanib did not significantly prolong OS compared with placebo (22.9 months vs. 20.5 months; HR, 0.91; 95\%CI, .71-1.16; 1-sided $\mathrm{P}=.224$ ), although the survival analysis was confounded by high rates of early cross over from placebo to pazopanib [23]. The COMPARZ study was a head-to-head comparison of 2VEGFRdirected TKIs in patients with previously untreated mccRCC [24]. In the trial 1,110 patients with mccRCC were randomly assigned 1:1 to pazopanib or sunitinib. Results showed the non inferiority of pazopanib compared with sunitinib in median PFS (8.4 months vs. 9.5 months; HR, 1.05; 95\% CI, 0.90- 1.22; $\mathrm{P}<.05$ ) [24]. Updated survival results showed similar median OS in the pazopanib and sunitinib groups (28.3 months vs. 29.1 months; HR, 0.92; 95\% CI, 0.79-1.06; P=.24) [17].

Given the comparable efficacy of pazopanib and sunitinib, differences in the toxicity profiles of these agents are important for selecting treatment. In the COMPARZ trial, patients in the pazopanib arm were less likely than sunitinib-treated patients to experience fatigue (55\% vs. $63 \%)$, hand-foot syndrome $(29 \%$ vs. $50 \%$ ), and thrombocytopenia (41\% vs. $78 \%$ ) [24]. However, patients in the pazopanib group were more likely than sunitinib treated patients to experience increased ALT levels (60\% vs. $43 \%$ ), changes in hair color ( $30 \%$ vs. $10 \%$ ), weight loss (15\% vs. $6 \%$ ), and alopecia(14\% vs. $8 \%$ ). An analysis of 14 health-related quality-of life (HRQOL) domains favored pazopanib during the first 6 months of treatment for 11 of the 14 factors $(\mathrm{P}<.05$ for all 11 comparisons). The effects of treatment on the remaining 3HRQOL factors were comparable between groups.

\section{Bevacizumab plus IFN- $\alpha$}

Bevacizumab is a monoclonal antibody that binds extracellular VEGF-A and prevents it from binding to VEGFR at the cell surface [25]. Bevacizumab was approved in combination with IFN- $\alpha$ for the first-line treatment of mRCC based on results of the AVOREN trial [25-27]. In the trial of 649 patients with treatment naïve mRCC, the median PFS was 10.2 months in patients treated with intravenous (IV) bevacizumab plus IFN- $\alpha$ compared with 5.4 months in patients treated with IFN- $\alpha$ alone (HR, 0.63; 95\% CI, 0.52-0.75; P=.0001) [26]. However, the median OS was 23.3 months and 21.3 months for patients treated with IFN- $\alpha$ with and without bevacizumab, respectively (HR, 0.91; 95\% CI, 0.76-1.10; $\mathrm{P}=.3360$ ) [27]. The treatment-cross over rate was high $(>55 \%)$ in both arms during follow-up, which may have confounded the survival analysis. Fatigue and asthenia, both 
well-recognized class effects of IFN- $\alpha$ therapy, were the most commonly reported grade 3-4 AEs in both treatment arms.

Additional grade3-4 AEs associated with bevacizumab included proteinuria (8\%) and hypertension (6\%) [27]. Additionally, the Cancer and Leukemia Group B (CALGB) 90206 trial, identified grade 2 or higher hypertension as a potential marker for response to bevacizumab plus IFN- $\alpha$ combination therapy [28]. Indeed, in the bevacizumab plus IFN- $\alpha$ group, patients who developed grade 2 or higher hypertension $(n=75)$ had significantly prolonged PFS (13.2 months vs. 8.0 months; $\mathrm{P}<.001)$ and $\mathrm{OS}(41.6$ months vs. 16.2 months; $\mathrm{P}<.001)$ compared with those who did not develop hypertension $(n=291)$. The combination of IV bevacizumab and IFN is now used less commonly than the oral VEGFRTKIs, which are easier to administer [4]. Therefore; the choice of anti-VEGF therapy for most patients with previously untreated mRCC is now between sunitinib and pazopanib.

\section{Temsirolimus}

Temsirolimus disrupts angiogenesis, apoptosis, and cell growth by blocking mTOR activity and inhibiting the phosphoinositide 3-kinase (PI3K) /AKT /mTOR intracellular signaling pathway [1,2]. Temsirolimus was approved for the first-line treatment of advanced RCC based on findings of the phase 3 Global ARCC Trial [29,30]. The trial enrolled 626 treatment naïve mRCC patients with poor prognosis, defined as the presence of at least 3 of 6 risk factors (modified from the MSKCC criteria) [29]. Elevated LDH, Anemia, Hypercalcemia Short disease-free interval, Karnofsky performance Score $\leq 70 \%$ multiple metastatic sites.

Patients were randomly assigned to temsirolimus, IFN- $\alpha$, or both [29]. The median OS was 10.9 months in the temsirolimus group, 8.4 months in the combination therapy group, and 7.3 months in the IFN- $\alpha$ group. Therefore, temsirolimus immunotherapy significantly improved OS compared with IFN- $\alpha$ alone (HR, 0.73; 95\% CI, 0.58-0.92; P=.008). However, no statistical difference was observed between combination therapy and IFN- $\alpha$ alone (HR, 0.96; 95\% CI, 0.76-12.0; P=.70). In addition, the median PFS was statistically similar regardless of treatment with temsirolimus (5.5 months), temsirolimus plus IFN- $\alpha$ (4.7 months), or IFN- $\alpha$ alone (3.1 months). Temsirolimus mono therapy was associated with fewer grade 3-4 AEs than were combination therapy or IFN- $\alpha$ alone. The most common grade 3-4 AEs in patients treated with temsirolimus were anemia (20\%), asthenia (11\%), hyperglycemia (11\%), and dyspnea (9\%) [29].

\section{Selecting Second- And Subsequent-Line Therapy}

\section{Treatment Sequencing and the Continuum of mRCC Care}

Advances in targeted therapy form RCC have extended survival and increased the number of patients who are eligible for 2 or 3 lines of therapy [30]. As a result, it is critical to plan a cross the continuum of care because the choice of initial therapy affects options for later treatment. The goals of optimal treatment sequencing are to maximize long-term response, minimize side effects, preserve quality of life, and managem RCC as a chronically treatable condition [31].

\section{Recommendations for Second- and Subsequent-Line Treatment}

Evidence supporting the optimal sequence of agents targeting VEGF, mTOR, and OPD-1 and its ligand (PD-L1) is beginning to emerge [31]. The NCCN guideline organizes the recommendations for second-and subsequent-line therapy based on prior systemic treatment, including cytokine-based therapy or TKI therapy (Table 3) [1]. The key safety and efficacy data supporting the use of several Category 1 options for second and subsequent line therapy are summarized in the following section. Supportive-care measures should also be incorporated into the treatment plan for each patient. When possible, the NCCN recommends considering patients for referral to a clinical trial 1.

Table 3: Recommendations for Subsequent therapy in Advanced RCCa Agent.

\begin{tabular}{|c|c|}
\hline Agent & Category/Preference \\
\hline Cabozantinib & $\begin{array}{c}\text { Category } 1 \text { after prior TKI therapy, } \\
\text { preferred }\end{array}$ \\
\hline Nivolumab & $\begin{array}{c}\text { Category } 1 \text { after prior TKI therapy, } \\
\text { preferred }\end{array}$ \\
\hline Axitinib & Category 1 after prior systemic therapy \\
\hline Lenvatinib/everolimus & Category 1 after prior systemic therapy \\
\hline Everolimus & Category 1 after prior TKI therapy \\
\hline Pazopanib & $\begin{array}{c}\text { Category } 1 \text { after prior cytokine therapy } \\
\text { Category } 2 \mathrm{~A} \text { after prior TKI therapy }\end{array}$ \\
\hline Sorafenib & $\begin{array}{l}\text { Category } 1 \text { after prior cytokine therapy } \\
\text { Category } 2 \mathrm{~A} \text { after prior TKI therapy }\end{array}$ \\
\hline Sunitinib & $\begin{array}{l}\text { Category } 1 \text { after prior cytokine therapy } \\
\text { Category } 2 \mathrm{~A} \text { after prior TKI therapy }\end{array}$ \\
\hline Bevacizumab & $\begin{array}{l}\text { Category } 2 \mathrm{~A} \text { after prior cytokine therapy } \\
\text { Category } 2 \mathrm{~B} \text { after prior TKI therapy }\end{array}$ \\
\hline Temsirolimus & $\begin{array}{c}\text { Category } 2 \mathrm{~A} \text { after prior cytokine therapy } \\
\text { Category } 2 \mathrm{~B} \text { after prior TKI therapy }\end{array}$ \\
\hline High-doseIL-2 & $\begin{array}{c}\text { Category 2B after atleast } 1 \text { prior systemic } \\
\text { therapy }\end{array}$ \\
\hline
\end{tabular}

Patients with relapsed or unrespectable stage IV disease with predominant clear-cell histology. IL-2=interleukin 2; TKI=tyrosine kinase inhibitor. Derived from National Comprehensive Cancer Network (NCCN) Clinical Practice Guidelines in Oncology for Kidney Cancer, v 2.2017. 


\section{Cancer Therapy \& Oncology International Journal}

\section{Cabozantinib}

Cabozantinib is a multikinase inhibitor that targets VEGFR-2 and MET 2. In the phase 3 METEOR trial, 658 patients with mRCC who progressed after prior VEGFRTKI therapy were randomly assigned $1: 1$ to cabozantinib $60 \mathrm{mg} /$ day or everolimus $10 \mathrm{mg} /$ day [32]. Most patients were s classified by MSKCC risk criteria as favorable (43\%-46\%) or intermediate risk (40\%-42\%). More than $25 \%$ of patients had prior treatment with 2 or more VEGFRTKIs. Cabozantinib was associated with a $42 \%$ reduction in the risk of disease progression compared with everolimus [32]. The most common grade 3-4 AEs were hypertension (15\%), diarrhea (13\%), and fatigue $(11 \%)$ in the cabozantinib group, and anemia (17\%), fatigue (7\%), and hyperglycemia $(5 \%)$ in the everolimus group [33]. In a planned interim analysis, cabozantinib was estimated to improve median os by $33 \%$ compared with everolimus [32]. The recently published final results from the METEOR trial reveal that cabozantinib increased OS, delayed disease progression, and improved the objective response rate compared with everolimus (Table 4) [33].

Table 4: METEOR-Second-Line Cabozantinib versus Everolimus in $\mathrm{mRCC}$.

\begin{tabular}{|c|c|c|c|c|}
\hline & Cabozantinib & Everolimus & HR (95\%CI) & P Value \\
\hline $\begin{array}{c}\text { Median } \\
\text { PFS }\end{array}$ & 7.4 months & 3.9 months & $\begin{array}{c}0.51(0.41- \\
0.62)\end{array}$ & $<.0001$ \\
\hline $\begin{array}{c}\text { Median } \\
\text { OS }\end{array}$ & 21.4 months & 16.5 months & $\begin{array}{c}0.66(0.53- \\
0.83)\end{array}$ & .00026 \\
\hline ORR & $17 \%$ & $3 \%$ & -- & $<.0001$ \\
\hline
\end{tabular}

$\mathrm{CI}=$ confidence interval; $\mathrm{HR}=$ hazard ratio; $\mathrm{ORR}=$ objective response rate; $\mathrm{OS}=$ overall survival; $\mathrm{PFS}=$ progression -free survival. Cabozantinib versus everolimus in advanced renalcell carcinoma. METEOR Investigators. Cabozantinib versus everolimus in advanced renal cell carcinoma (METEOR): final results from a randomized, open-label phase 3 trials [34].

\section{Nivolumab}

Nivolumab is a monoclonal antibody that blocks the interaction between PD-1 and PD-L1 to disrupt negative signaling and restore the T-cell antitumor response $[7,35]$. Nivolumab was approved for the second-line treatment of mRCC based on the Check Mate 025 trial. The phase 3 trial enrolled 821 patients with advanced ccRCC who received 1 or more lines of prior systemic therapy, excluding mTOR inhibitors [35]. Patients were randomly assigned $1: 1$ to IV nivolumab $3 \mathrm{mg} / \mathrm{kg}$ given every 2 weeks or oral everolimus $10 \mathrm{mg} /$ day. The Check Mate 025 trial was the first trial to demonstrate a significant survival benefit in the second-line mRCC setting (Table 5). The survival benefit of nivolumab was consistent for all patients, regardless of baseline PD-L1 expression. Nivolumab also significantly improved objective response rate by 5 -fold compared with everolimus. Median PFS, however, was comparable. In the safety analysis, nivolumab was associated with fewer grade 3-4 AEs than was everolimus (19\% vs. $37 \%$ ), as well as a lower rate of treatment discontinuation due to AEs ( $8 \%$ vs. $13 \%$ ). The most common grade 3-4 AEs in the nivolumab group were fatigue $(2 \%)$ and anemia (2\%) [35].

Table 5: Check Mate 025-Second-Line Nivolumab versus Everolimusin mRCC.

\begin{tabular}{|c|c|c|c|c|}
\hline & Nivolumab & Everolimus & $\begin{array}{c}\text { HRa } \\
\mathbf{9 5 \%} \mathbf{9})\end{array}$ & P Value \\
\hline Median OS & $\begin{array}{c}25.0 \\
\text { months }\end{array}$ & 19.6 months & $\begin{array}{c}0.73(0.57- \\
0.93)\end{array}$ & .002 \\
\hline Median PFS & 4.6 months & 4.4 months & $\begin{array}{c}0.88(0.75- \\
1.03)\end{array}$ & .11 \\
\hline ORR & $25 \%$ & $5 \%$ & $\begin{array}{c}5.98(3.68- \\
9.72)\end{array}$ & $<.001$ \\
\hline
\end{tabular}

A Odds ratio for ORR. $\mathrm{CI}=$ confidence interval; $\mathrm{HR}=$ hazard ratio; ORR=overall response rate; OS=overall survival; $\mathrm{PFS}=$ progression-free survival. Nivolumab versus everolimus in advanced renal-cell carcinoma.

\section{Axitinib}

The multicenter, randomized, phase 3 AXIS trial compared second-line treatment with axitinib $5 \mathrm{mg}$ twice daily versus sorafenib 400mg twice daily in 723 patients with mRCC previously treated with sunitinib (54\%), cytokines $(35 \%)$, or other systemic therapy [36]. Compared with sorafenib, axitinib significantly reduced the risk of disease progression by $33 \%$ for all patients (HR, 0.67), regardless of prior treatment type. Patients in the axitinib group were more likely than those in the sorafenib group to experience hypertension (40\% vs. $29 \%$ ), fatigue (39\% vs. $32 \%$ ), dysphonia (31\% vs. $14 \%$ ), and hypothyroidism (19\% vs. $8 \%$ ). However, patients treated with axitinib were less likely than those in the sorafenib group to develop hand-foot syndrome $(27 \%$ vs. $51 \%)$, rash $(13 \%$ vs. $32 \%$ ), alopecia ( $4 \%$ vs. $32 \%$ ), and anemia (35\% vs. $52 \%$ ) [36]. In an updated survival analysis, the median OS was 20.1 month in the axitinib group and 19.2 months in the sorafenib group (HR, 0.97; 95\% CI, 0.80-1.17) [37].

\section{Lenvatinib plus everolimus.}

The combination of lenvatinib plus everolimus is an FDAapproved regimen that combines VEGF and mTOR inhibition in the second-line treatment of mRCC [5]. The approval was based on results from Study 205, which evaluated lenvatinib $24 \mathrm{mg}$ / day, everolimus $10 \mathrm{mg}$ /day, or lenvatinib plus everolimus (18mg/ day and $5 \mathrm{mg}$ /day, respectively) in 153 patients with $\mathrm{mRCC}$ who had received prior treatment with at least 1 VEGF-targeted agent $[5,38]$. The primary endpoint was PFS. Combined treatment with lenvatinib plus everolimus significantly improved median PFS compared with everolimus alone, but not when combination therapy was compared with lenvatinib alone. The rate of grade 3-4 AEs were lower with everolimus alone (50\%) than with 


\section{Cancer Therapy \& Oncology International Journal}

lenvatinib (79\%) or lenvatinib plus everolimus (71\%). In the combination group, diarrhea (20\%) was the most common grade 3-4AE [38]. A recent updated survival analysis from Study 205 suggested a trend toward improved OS with lenvatinib plus everolimus compared with everolimus alone (HR, 0.59; 95\% CI, 0.36-0.96; $\mathrm{P}=.065$ ) [39]. The median OS was 25.5 months with combination therapy, 19.1 months with lenvatinib alone, and 15.4 months with everolimus alone.

\section{Additional Considerations for Treatment Sequencing}

Little compelling evidence is available to date to guide the selection of third-line therapy; however, several clinical trials have explored the optimal sequence of multiple targeted therapies in mRCC. Some trials support the use of sorafenib as third-line therapy in patients previously treated with a VEGFRTKI/mTOR inhibitor sequence $[40,41]$. Alternatively, a subgroup analysis of the RECORD-1 study suggests that thirdline everolimus prolongs PFS among patients who received 2 previous VEGFRTKIs [42]. Future research may focus on potential biomarkers to guide subsequent treatment selection. For example, the duration of response to a VEGFRTKI may be useful to guide subsequent treatment; indeed, evidence suggests that patients with slow progression after 1VEGFRTKI may benefit from switching to an alternate VEGFRTKI, where as those with rapid progression may benefit from an agent with a different mechanism of action. As additional clinical evidence emerges, future guide lines may provide a clearer frame work for the optimal sequence of 2 or 3 (or more) targeted therapies and combination regimens in mRCC [10].

\section{Looking Ahead: Ongoing Trials of First-Line Treatment}

Building on evidence of antitumor activity in previously treated patients with mRCC, many emerging regimens are now being evaluated in the first-line setting. 8.44 The recent phase 2 ALLIANCE A031203 trials compared initial targeted therapy with cabozantinib versus sunitinib in 157 poor and intermediaterisk patients with mRCC. The median PFS was 8.2 months with cabozantinib and 5.6 months for sunitinib, indicating a $31 \%$ reduction in the risk of disease progression or death with firstline cabozantinib compared with sunitinib (HR, 0.69; 95\% CI, 0.48-0.98; 1-sided $\mathrm{P}=.012$ ). Nivolumab and several other immune check point inhibitors are also under evaluation for the first-line treatment of mRCC, including agents that currently are approved for other tumor types (atezolizumab, ipilimumab,

pembrolizumab) and the investigational PD-L1 inhibitor avelumab (Table 6).

Table 6: Findings from ongoing phase 3 trials may clarify the role of novel check point inhibitor-based combination regimens relative to standard VEGFRTKI therapy in.

\begin{tabular}{|c|c|c|c|}
\hline Trial & Comparators & Primary Endpoint (s) & Secondary Endpoints \\
\hline NCT02231749 (Check Mate 214) & $\begin{array}{c}\text { Nivolumab/ipilimumab vs. } \\
\text { sunitinib monotherapy }\end{array}$ & PFS;OS & ORR; Safety \\
\hline NCT02420821 & $\begin{array}{c}\text { Atezolizumab/bevacizumab vs. } \\
\text { sunitinib monotherapy }\end{array}$ & $\begin{array}{c}\text { PFS; OS in patients with } \\
\text { detectable PD-L1expression }\end{array}$ & $\begin{array}{c}\text { PFS by independent review; ORR; } \\
\text { DOR; safety; QOL;PK }\end{array}$ \\
\hline $\begin{array}{c}\text { NCT02684006 (JAVELIN Renal } \\
\text { 101) }\end{array}$ & $\begin{array}{c}\text { Avelumab/axitinib vs. sunitinib } \\
\text { monotherapy }\end{array}$ & $\begin{array}{c}\text { OS; ORR; DCR; TTR; DOR; PK; } \\
\text { antidrug antibody development; } \\
\text { biomarkers; quality of life }\end{array}$ \\
\hline $\begin{array}{c}\text { NCT02853331(MK-3475-426/ } \\
\text { KEYNOTE-426) }\end{array}$ & $\begin{array}{c}\text { Pembrolizumab/axitinib vs. } \\
\text { sunitinib monotherapy }\end{array}$ & PFS;OS & ORR; DCR; safety \\
\hline
\end{tabular}

DCR: Disease control rate; DOR: Duration of Response; ORR: over all response rates; OS: overall survival; PDL1: programmed death ligand 1; PFS: Progression free survival; PK: pharmacokinetics; QOL: quality of life; TTR: time to treatment response.

\section{Conclusion}

Since late 2005, the management of mRCC has evolved from a choice between 2 nonspecific cytokine-based immuno therapies to a complex algorithm involving 10 additional targeted therapies with diverse mechanisms of action. The choice for firstline therapy depends on an individualized assessment of tumor histology, prognostic risk, and patient preferences. With new treatments contributing to improved survival, more patients are now candidates for second and subsequent-line treatment. At every treatment stage, managing immune-mediated toxicities and non specific AEs is critical for maximizing therapeutic efficacy while preserving quality of life. Ongoing phase 3 trials are testing new check point inhibitor-based combination regimens against standard VEGFRTKI therapy in the first-line setting. Determining which patients with mRCC are most likely to benefit from specific sequences of treatment will be important as options for targeted therapy continue to expand.

\section{References}

1. Bamias Aristotle, Escudier B, Sternberg CN, Zagouri F, Dellis A, et al. (2017) "Current Clinical Practice Guidelines for the Treatment of Renal Cell Carcinoma: A Systematic Review and Critical Evaluation."The Oncologist 22(6): 667-679.

2. BedkeJ, Gauler T, Grünwald V, Hegele A, Herrmann E, et al. (2017) Systemic therapy in metastatic renal cell carcinoma. World J Urol 35(2): 179-188. 


\section{Cancer Therapy \& Oncology International Journal}

3. Choueiri Toni K, Robert J Motzer (2017) "Systemic therapy for metastatic renal-cell carcinoma."New England Journal of Medicine 376(4): 354-366.

4. Greef B, Eisen T (2016) Medical treatment of renal cancer: new horizons. Br J Cancer 115(5): 505-516.

5. Motzer Robert J, Hutson TE, Ren M, Dutcus C, Larkin J, et al. (2016) "Independent assessment of lenvatinib plus everolimus in patients with metastatic renal cell carcinoma. Lancet Oncology 17(1): e4-e5.

6. Rini Brian I, Halabi S, Rosenberg JE, Stadler WM, Vaena DA, et al. (2010) "Phase III trial of bevacizumab plus interferon alfa versus interferon alfa monotherapy in patients with metastatic renal cell carcinoma: final results of CALGB90206."Journal of clinical oncology 28(13): 2137-2143

7. Massari F, Santoni M, Ciccarese C, Santini D, Alfieri S, et al. (2015) "PD1 blockade therapy in renal cell carcinoma: current studies and future promises."Cancer treatment reviews 41(2):114-121.

8. Motzer Robert J, Bernard Escudier, Toni K Choueiri (2016) “Treatment of Advanced Renal-Cell Carcinoma."The New England journal of medicine 374(9): 889-890.

9. Escudier B, Porta C, Schmidinger M, N Rioux-Leclercq, A Bex, et al. (2016) ESMO Guidelines Committee. Renal cell carcinoma: ESMO Clinical Practice Guidelines for diagnosis, treatment and follow-up. Ann Oncol 27(5): v58-v68.

10. Hudes GR, Carducci MA, Choueiri TK, Peg Esper, Rashmi Kumar, et al. (2011) NCCNT ask Force report: optimizing treatment of advanced renal cell carcinoma with molecular targeted therapy. J Natl Compr Canc Netw 9(1): S1-S29.

11. Motzer RJ, Mazumdar M, Bacik J, Berg W, Amsterdam A (1999) Survival and prognostics tratification of 670 patients with advanced renal cell carcinoma. J Clin Oncol 17(8): 2530-2540.

12. Motzer RJ, Bacik J, Murphy BA, Russo P, Mazumdar M (2002) Interferonalfaasa comparative treatment for clinical trials of new therapies against advanced renal cell carcinoma. J Clin Oncol 20(1): 289-296.

13. Heng DYC, Xie W, Regan MM, Warren MA, Golshayan AR, et al. (2009) Prognostic factors for overall survival in patients with metastatic renal cell carcinoma treated with vascular endothelial growth factortargeted agents: results from a large, multicenter study. J Clin Oncol 27(34): 5794-5799.

14. Heng DYC, Xie W, Regan MM, Harshman LC, Bjarnason GA, et al (2013) External validation and comparison with other models of the International Metastatic Renal-Cell Carcinoma Database Consortium prognostic model: a population-based study. Lancet Oncol 14(2): 141148.

15. KoJJ, Xie W, Kroeger N, Lee JL, Rini BI et al. (2015) The International Metastatic Renal Cell Carcinoma Database Consortium model as a prognostic tool in patients with metastatic renal cell carcinoma previously treated with first-line targeted therapy: a population-based study. Lancet Oncol 16(3): 293-300.

16. Wells JC, Stukalin I, Norton C, Srinivas S, Lee JL, et al. (2017) Third-line targeted therapy in metastatic renal cell carcinoma: results from the International Metastatic Renal Cell Carcinoma Database Consortium. Eur Urol 71(2): 204-209.

17. Motzer RJ, Hutson TE, Mc Cann L, Deen K, Choueiri TK (2014) Over all survival in renal-cell carcinoma with pazopanib versus sunitinib. $\mathrm{N}$ Engl J Med 370(18): 1769-1770.

18. Gore ME, Szczylik C, Porta C, Bracarda S, Bjarnason GA, et al. (2015) Final results from the large sunitinib global expanded-accesstrial in metastatic renal cell carcinoma. Br J Cancer 113(1): 12-19.

19. Motzer RJ, Hutson TE, Tomczak P, Michaelson MD, Bukowski RM, et al. (2007) Sunitinib versus interferon alfa in metastatic renal-cell carcinoma. N Engl J Med 356(2): 115-124.

20. Motzer RJ, Hutson TE, Tomczak P, Michaelson MD, Bukowski RM, et al (2009) Overall survival and updated results for sunitinib compared with interferon alfa in patients with metastatic renal cell carcinoma. J Clin Oncol 27(22): 3584-3590.

21. Sternberg CN, Davis ID, Mardiak J, Szczylik C, Lee E, et al. (2010) Pazopanib in locally advanced or metastatic renal cell carcinoma: results of a randomized phase III trial. J Clin Oncol 28(6): 1061-1068.

22. Pazopanib (2009) Research Triangle Park, NC: Novartis Pharmaceuticals Corporation, New Jersey, USA.

23. Sternberg CN, Hawkins RE, WagstaffJ, Salman P, Mardiak J, et al. (2013) A randomised, double-blind phase III study of pazopanib in patients with advanced and/ or metastatic renal cell carcinoma: final over all survival results and safety update. Eur J Cancer 49(6): 1287-1296.

24. Motzer RJ, Hutson TE, Cella D, Reeves J, Hawkins R, et al. (2013) Pazopanib versus sunitinib in metastatic renal-cell carcinoma. $\mathrm{N}$ Engl J Med 369(8): 722-731.

25. Bevacizumab (2015) South San Francisco, Genentech, CA, USA

26. Escudier B, Pluzanska A, Koralewski P, Ravaud A, Bracarda S, et al. (2007) AVOREN Trial investigators. Bevacizumab plus interferon alfa2 a for treatment of metastatic renal cell carcinoma: a randomised, double-blind phase III trial. Lancet 370(9605): 2103-2111.

27. Escudier B, Bellmunt J, Négrier S, Bajetta E, Melichar B, et al. (2010) Phase III trial of bevacizumab plus interferon alfa- 2 a in patients with metastatic renal cell carcinoma (AVOREN): final analysis of overall survival. J Clin Oncol 28(13): 2144-2150.

28. Rini BI, Halabi S, Rosenberg JE, Stadler WM, Vaena DA, et al. (2010) Phase III trial of bevacizumab plus interferon alfa versus interferon alfa monotherapy in patients with metastatic renal cell carcinoma: final results of CALGB90206. J Clin Oncol 28(13): 2137-2143.

29. Hudes G, Carducci M, Tomczak P, Dutcher J, Figlin R, et al. (2007) Global ARCC Trial. Temsirolimus, interferon alfa, or both for advanced renalcell arcinoma. N Engl J Med 356(22): 2271-2281.

30. Temsirolimus (2016) PA Pfizer, Inc. Philadelphia, USA.

31. Incorvaia L, Bronte G, Bazan V, Badalamenti G, Rizzo S, et al. (2016) Beyond evidence-based data: scientific rationale and tumor behavior to drive sequential and personalized therapeutic strategies for the treatment of metastatic renal cell carcinoma. Oncotarget $7(16)$ : 21259-21271.

32. Choueiri TK, Escudier B, Powles T, Tannir NM, Mainwaring PN, et al (2015) METEOR Investigators. Cabozantinib versus everolimus in advanced renal-cell carcinoma. N Engl J Med 373(19): 1814-1823.

33. Choueiri TK, Escudier B, Powles T, Tannir NM, Mainwaring PN et al METEOR Investigators. Cabozantinib versus everolimus in advanced renal-cellcarcinoma (METEOR): final results from a randomized, openlabel, phase 3 trial. Lancet Oncol 17(7): 917-927.

34. Mennitto A, Grassi P, Ratta R, Verzoni E, Prisciandaro M, et al. (2016) Nivolumab in the treatment of advanced renal cell carcinoma: clinical trial evidence and experience. Ther Adv Urol 8(5): 319-326.

35. Motzer RJ, Escudier B, McDermott DF, et al. (2015) CheckMate 025 Investigators. Nivolumab versus everolimus in advanced renal-cell carcinoma. N Engl J Med 373(19):1803-1813.

36. Rini BI, Escudier B, Tomczak P, Kaprin A, Szczylik C, et al. (2011) Comparative effectiveness of axitinib versus sorafenibin advanced renal cell carcinoma (AXIS): a randomized phase 3trial. Lancet 378(9807): 1931-1939.

37. Motzer RJ, Escudier B, Tomczak P, Hutson TE, Michaelson MD, et 


\section{Cancer Therapy \& Oncology International Journal}

al. (2013) Axitinib versus sorafenib as second-line treatment for advanced renal cell carcinoma: overall survival analysis and updated results from a randomised phase 3 trial. Lancet Oncol 14(6): 552-562.

38. Motzer RJ, Hutson TE, Glen H, M Dror Michaelson, Ana Molina, et al. (2015) Lenvatinib, everolimus, and the combination in patients with metastatic renal cell carcinoma: a randomised, phase 2, open-label, multicentre trial. Lancet Oncol 16(15): 1473-1482.

39. Hutson TE, Dutcus CE, Ren M, Mahadi Ali Baig, Mayer N, et al. (2016) Subgroup analyses and updated overall survival from the phase II trial of lenvatinib (LEN), everolimus(EVE), and LEN+EVE in metastatic renalcell carcinoma(mRCC). Presented at the American Society of Clinical Oncology (ASCO) 2016 Annual Meeting Chicago, IL, USA.
40. DiLorenzo G, Buonerba C, Federico P, Rescigno P, Milella M, et al. (2010) Third-lines Sorafenib after sequential therapy with sunitinib and mTOR inhibitors in metastatic renal cell carcinoma. Eur Urol 58(6): 906-911.

41. Motzer RJ, PortaC, Vogelzang NJ, Sternberg CN, Szczylik C, et al. (2014) Dovitinib versus sorafenib for third-line targeted treatment of patients with metastatic renal cell carcinoma: an open label, randomized phase 3 trial. Lancet Oncol 15(3): 286-296.

42. Calvo E, Escudier B, Motzer RJ, Oudard S, Hutson TE, et al. (2012) Everolimus in metastatic renal cell carcinoma: subgroup analysis of patients with 1 or 2 previous vascular endothelial growth factor receptor-tyrosine kinase inhibitor therapies enrolled in the phase III RECORD-1 study. Eur J Cancer 48(3): 333-339.

\section{Your next submission with Juniper Publishers will reach you the below assets}

- Quality Editorial service

- Swift Peer Review

- Reprints availability

- E-prints Service

- Manuscript Podcast for convenient understanding

- Global attainment for your research

- Manuscript accessibility in different formats

( Pdf, E-pub, Full Text, Audio)

- Unceasing customer service

Track the below URL for one-step submission https://juniperpublishers.com/online-submission.php 